$\mathbb{T}$ periodica polytechnica

Mechanical Engineering

$5 2 / 1 ( 2 0 0 8 ) \longdiv { 3 5 } 4 2$

doi: 10.3311/pp.me.2008-1.06

web: http://www.pp.bme.hu/me

(c) Periodica Polytechnica 2008

RESEARCH ARTICLE

\section{Producing metal matrix syntactic foams by pressure infiltration}

\author{
Imre Norbert Orbulov / János Dobránszky
}

Received 2008-01-18

\begin{abstract}
This paper presents the possibility of syntactic foam production by pressure infiltration technology. Syntactic foams have low density and relatively high strength. Therefore they can be the material of many important parts in automotive technology or in aviation. The parameters of infiltration were studied and physical and mechanical investigations were performed. Microscopic investigations showed almost perfect infiltration at the applied infiltration pressure. The densities of the foams were significantly decreased. Low density ensures good specific properties and economical energy consuming in the case of moving the parts. Syntactic foams showed a plateau region in their upsetting diagrams and absorbed a high energy during upsetting. The effect of aspect ratio was also investigated. Specimens with higher aspect ratios showed lower peak stress, lower plateau level and higher modulus of elasticity.
\end{abstract}

\section{Keywords}

metal matrix composite $\cdot$ pressure infiltration $\cdot$ metallic foam . syntactic foam · ceramic microballoon · hollow sphere.

\section{Acknowledgement}

Our Metal Matrix Composites Laboratory is supported by grant \# GVOP 3.2.1-2004-04-0145/3.0. The investigations were supported by Hungarian Research Fund, NKTH-OTKA K69122. Special thanks to Róbert Tóth and C. H. Erbslöh Hungária Speciality and Industrial Minerals Ltd. for providing microballoons.

\section{Imre Norbert Orbulov}

Department of Materials Science and Engineering, BME, H-1111 Budapest, Goldmann Gy. tér 3, Hungary

e-mail: orbulov@gmail.com

\section{János Dobránszky}

Research Group for Metals Technology of the Hungarian Academy of Sciences, H-1111 Budapest, Goldmann Gy. tér 3, Hungary

e-mail: dobi@eik.bme.hu

\section{Introduction}

Syntactic foams are closed cell foams, but they can also be classified as particle reinforced MMCs. The first publication on this material was presented in the late 1960s. Kallas and Chatten were among the first researchers, investigating the possibility of using polymer matrix syntactic foams as hulls of deep sea applications [1]. In the case of syntactic foams porosity is produced by introducing hollow spheres (microballoons) into the matrix material. These foams are good energy absorbers, mechanical dampers, have low weight, outstanding specific properties, localized failure, etc. They are used as energy absorbers, heat insulators (with polymer matrix), and sound absorbers or as hull material in deep-sea applications and aeronautics.

Syntactic foams with metal matrix are usually produced by blending method or by pressure infiltration. The advantage of blending method is the variable volume fraction of the filler. The main disadvantage is the non-uniform distribution of the particles (due to density mismatch between matrix and filler material). Ramachandra and Radhakrishna successfully produced syntactic foams by blending method and described the process parameters [2]. Pressure infiltration is used when high volume fraction and uniform distribution of the reinforcing particles or fibres are desired in MMCs. The most common matrix material is aluminium. For example Rohatgi et al. demonstrated the possibility of fly ash reinforced composite production and they showed that the increase of the volume fraction of particles increases the strength of the composite [3,4]. Balch and Dunand also produced syntactic foams with metal matrix by pressure infiltration and they studied their failure during upsetting [5, 6]. Palmer et al. (2007) also used pressure infiltration to produce syntactic foams with Al1350, Al5083 and Al6061 matrix. They characterized the foams by upsetting, tensile and bending tests [7].

For successful infiltration a threshold pressure must be assured by the infiltrating system. This pressure can be calculated by theoretical and experimental approaches for various systems. Bárczy and Kaptay (2005) developed a fully theoretical model for closely packed spheres based on the equilibrium of gravitational, capillary and outer forces. The model considered the 
effect of wetting angle, surface tension and volume fraction [8]. Trumble (1998) defined a hydraulic radius, which depended on the shape and the volume fraction of the fillers and calculated the threshold pressure by using the Young-Laplace equation [9]. The same was done by Rohatgi et al. (1998), but they defined an effective distance between the microballoons [3]. The base equation was the Young-Laplace equation again. If the required threshold pressure is smaller than 1 bar it can be generated by vacuum instead of pressure. Kiser et al. (1999) investigated the mechanical response of syntactic foams produced by vacuum assisted casting. And they also predicted the compressive strength of the foams in accordance with different stress fields [10]. Recently, the mathematical description of syntactic foams is important for the sake of correct and economic design, therefore Wu et al. (2007) predicted the compressive strength of aluminium based syntactic foams, showing the relation between the microballoon properties and the strength [11].

\section{Manufacturing method and materials}

Pressure infiltration method was used to produce various types of syntactic foams. A carbon steel container was coated with a thin carbon layer and filled up to half height with the filler. The carbon layer ensured the easy removing of the produced syntactic foam block after infiltrating. $\mathrm{An}\left(\mathrm{Al}_{2} \mathrm{O}_{3}\right)$ insulator layer was placed on top of the reinforcement. The role of this layer was to separate the matrix materials from the filler during the first part of the infiltrating procedure. Finally an aluminium block, as matrix material, was placed into the container. This time at least two thermocouples were put in place to control the process through temperature. Then the prepared and filled container was put into the pressure infiltration chamber (Fig. 1).

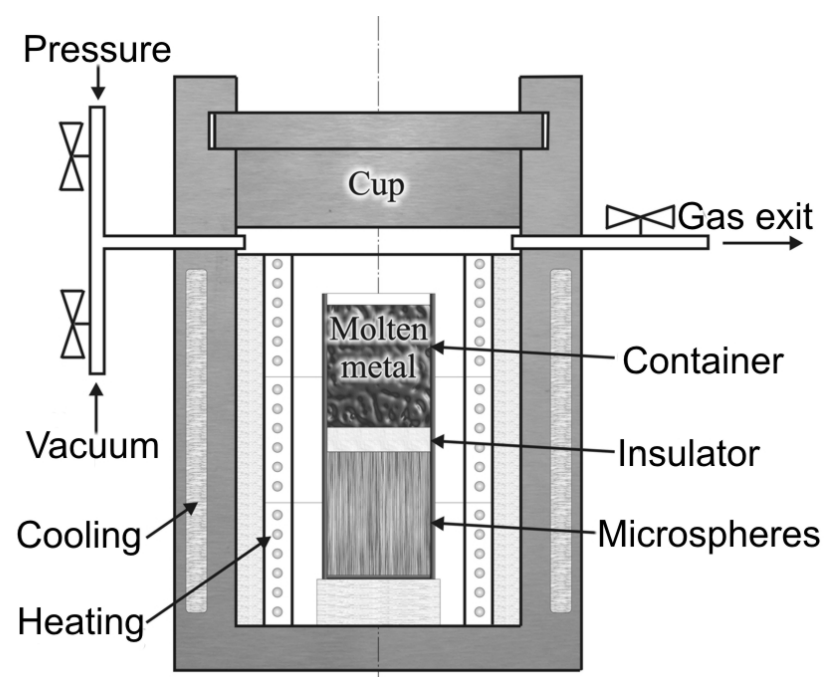

Fig. 1. Schematic structure of the infiltration unit

In this chamber, vacuum or gas pressure can be generated. Argon gas was used to provide the required threshold pressure for infiltrating. After inserting the container into the chamber, it was closed and evacuated. During the first part of the infiltration procedure heating began, and vacuum was maintained. The melted matrix metal formed a liquid cork above the reinforcement. Then Ar gas was let flow into the chamber and pressure was increased to a previously set value. The generated pressure difference above and under the liquid metal cork enforced the metal to infiltrate the reinforcement through the insulator layer. After infiltration the container was removed and cooled by water. After cooling the composite block was removed from the container and finally specimens were machined for the investigations.

In our work we used three types of filler materials each produced by Envirospheres Pty. Ltd. They are called E-Spheres SL150, SLG and SL300 (Fig. 2), their main properties are summarized in Table 1 . The microballons typically contained $36-40$ wt $\% \mathrm{Al}_{2} \mathrm{O}_{3}, 55-60 \mathrm{wt} \% \mathrm{SiO}_{2}, 1.4-1.6$ wt $\% \mathrm{TiO}_{2}, 0.4-0.5 \mathrm{wt} \%$ $\mathrm{Fe}_{2} \mathrm{O}_{3}$ and other oxides.

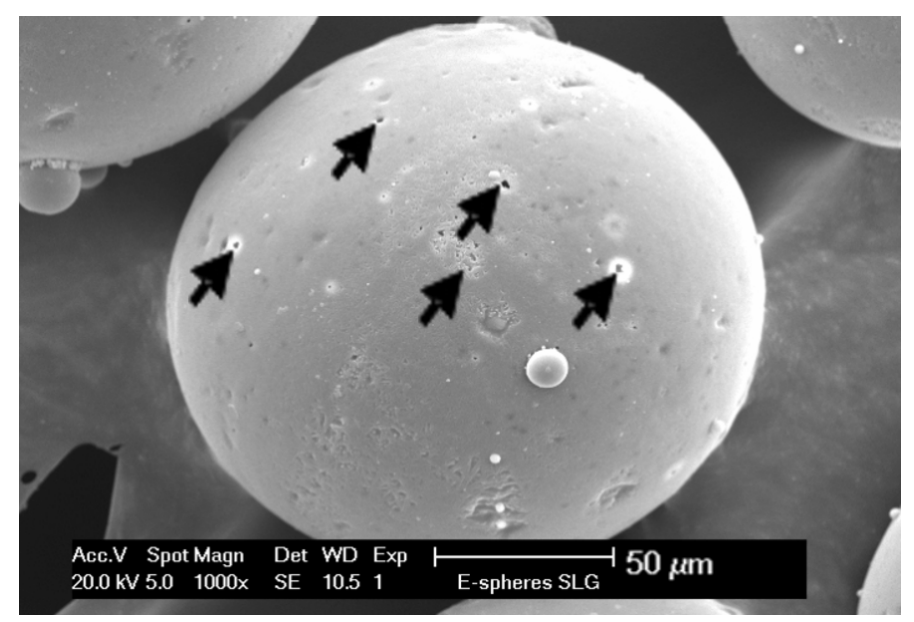

Fig. 2. Typical SEM picture of a SL150 ceramic microballoon

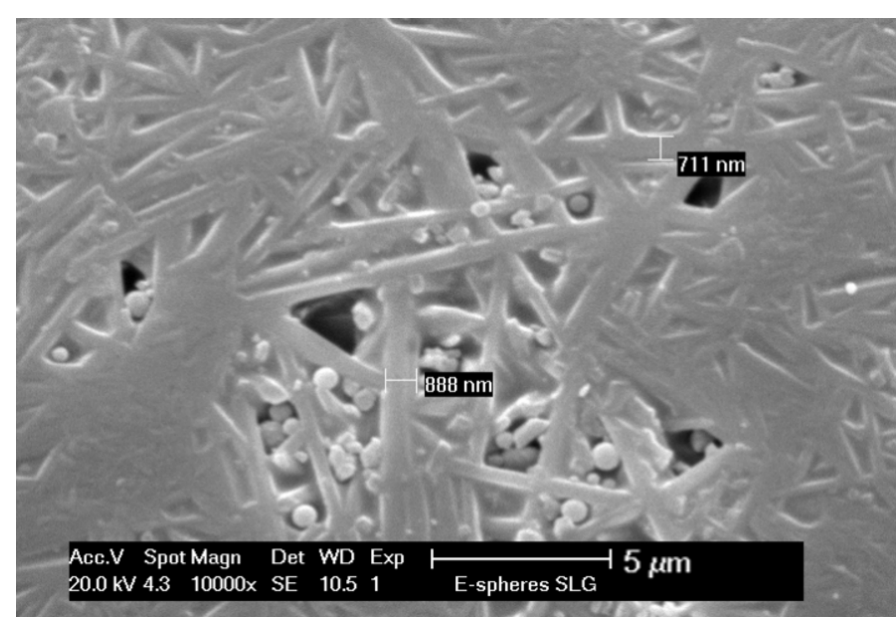

Fig. 3. High magnification SEM picture about the surface of a SL150 type microballoon

These microspheres were produced by sintering method. In Fig. 2 some very small porosities (marked by black arrows) can be observed. They were caused by the producing method, which used very small sticks as showed in Fig. 3. Due to very small dimensions the porosities were also small and did not cause problems during infiltration. The volume fraction of the filler maintained at $\sim 64$ vol\%. This correlated to "randomly close packed 
Tab. 1. Typical properties of E-spheres

\begin{tabular}{cccc}
\hline Type & $\begin{array}{c}\text { Average outer } \\
\text { diameter }\end{array}$ & $\begin{array}{c}\text { Average wall } \\
\text { thickness }\end{array}$ & $\begin{array}{c}\text { Average real } \\
\text { density }\end{array}$ \\
\hline & $(\boldsymbol{\mu m})$ & $(\boldsymbol{\mu m})$ & $\left.\mathbf{( k g m}^{-3}\right)$ \\
\hline SL150 & 100 & 3.69 & 637 \\
SLG & 130 & 5.35 & 691 \\
SL300 & 150 & 6.75 & 576 \\
\hline
\end{tabular}

equal spheres" structure, which can be reached by pouring the fillers into a container and putting them in order by tapping. It was proved experimentally that the volume fracture of the filler converges logarithmically to 64 vol\% according to the number of tapping.

As matrix material we used two types of aluminium alloys. During our first experiments AlSi12 alloy was used, which contains $\sim 12 \mathrm{wt} \%$ silicon and therefore has good castability, fluidity and relatively low melting point. Due to high Si content AlSi12 has higher flow stress, but also lower ductility. This indicated the use of A199.5 as a matrix material, which has better ductility, but lower strength and higher melting point.

With the two matrix materials and three fillers, six types of syntactic foams can be produced. Two blocks from each type (overall 12 blocks) were made. Each block was $36 \times 55 \times 360$ $\mathrm{mm}$ in size. They were designated according to their matrix and filler materials. For example Al-SL150-1 stands for the first syntactic foam block consisting A199.5 material as matrix and SL150 type microballoon as filler. The pressure infiltration has three main parameters, namely infiltration pressure, time and temperature of infiltration. The time was maintained at $30 \mathrm{~s}$, the other parameters are summarized in Table 2

Tab. 2. The parameters of the infiltrations

\begin{tabular}{|c|c|c|c|}
\hline \multirow[t]{3}{*}{ Designation } & \multicolumn{2}{|c|}{$\begin{array}{l}\text { Temperature at the } \\
\text { moment of infiltration }\end{array}$} & \multirow{3}{*}{$\begin{array}{c}\text { Infiltration } \\
\text { pressure } \\
\text { (kPa) }\end{array}$} \\
\hline & \multirow{2}{*}{$\begin{array}{c}\text { Microballoons } \\
\left.\text { ( }^{\circ} \mathrm{C}\right)\end{array}$} & \multirow{2}{*}{$\begin{array}{c}\text { Matrix } \\
\left({ }^{\circ} \mathrm{C}\right)\end{array}$} & \\
\hline & & & \\
\hline Al-SL150-1 & 695 & 720 & 434 \\
\hline Al-SL150-2 & 700 & 720 & 448 \\
\hline Al-SLG-1 & 680 & 720 & 441 \\
\hline Al-SLG-2 & 685 & 720 & 441 \\
\hline Al-SL300-1 & 690 & 720 & 359 \\
\hline Al-SL300-2 & 705 & 720 & 393 \\
\hline Average & 692.5 & 720 & 419 \\
\hline Scatter & 9.4 & 0 & 35.5 \\
\hline AISi-SL150-1 & 590 & 620 & 331 \\
\hline AISi-SL150-2 & 595 & 620 & 372 \\
\hline AISi-SLG-1 & 585 & 630 & 338 \\
\hline AISi-SLG-2 & 595 & 620 & 359 \\
\hline AISi-SL300-1 & 590 & 620 & 352 \\
\hline AISi-SL300-2 & 600 & 620 & 331 \\
\hline Average & 592.5 & 621.7 & 347 \\
\hline Scatter & 5.2 & 4.1 & 16.7 \\
\hline
\end{tabular}

In the case of A199.5 alloy the melting point is $\sim 660^{\circ} \mathrm{C}$ and therefore the superheating of the fillers and the matrix were $\sim 30^{\circ} \mathrm{C}$ and $\sim 60^{\circ} \mathrm{C}$ respectively. The superheating of the fillers ensures that the infiltrating material does not solidify during the infiltration. It also helps to fix the small porosities on the surface of the microballoons as this temperature is near their softening temperatures. The superheating of the matrix increases its fluidity and therefore the infiltration can be accomplished easier. The melting point of AlSi12 alloy is $\sim 570{ }^{\circ} \mathrm{C}$, so approximately the same superheating was applied in that case as showed in Table 2

The infiltration pressure is at least as important as the infiltration temperature and has a lower and an upper limit. The lower limit is the threshold pressure of the infiltration. This pressure is required to force the molten matrix material among the randomly closed packed microballoons. As we mentioned in the introduction, the value of the threshold pressure can be estimated by calculations based on theoretical and experimental approaches. Bárczy and Kaptay (2005) gives the threshold pressure from the equilibrium of gravitational $\left(\mathrm{F}_{g}\right)$, capillary $\left(\mathrm{F}_{c}\right)$ and outer $\left(\mathrm{F}_{0}\right)$ forces [8].

This model depends on the wetting angle $(\theta)$ between the material of the microballoons and matrix, on the surface tension $\left(\sigma_{l / g}\right)$ between the molten matrix and the surrounding gas phase, on the ratio of liquid/gas interface area to total infiltration area $\left(\varepsilon_{S}\right)$, on the radius $(\mathrm{R})$ of the microballoons and on the actual position (h) of the infiltrating front.

$$
p=\frac{\sqrt{3}}{3} \frac{\sigma_{l / g}}{R} \frac{\pi}{\varepsilon_{s}}\left(\frac{h}{R}-1-\cos \theta\right)
$$

Trumble (1998) uses the Young-Laplace equation as a starting point and defines a hydraulic radius $\left(r_{h}\right)$, which expresses the ratio of volume and surface area of porosity between microballoons. This ratio depends on the volume fraction $\left(\mathrm{V}_{m b}\right)$ and the diameter (D) of the microballoons and on a shape factor $(\lambda$, $\lambda=1$ in the case of spheres). The Young-Laplace equation also depends on the surface tension and the wetting angle of the system. With these data one can express the threshold pressure [9].

$$
p=\frac{2 \sigma_{l / g} \cos \theta}{r_{h}}=\frac{12 \lambda V_{m b} \sigma_{l / g} \cos \theta}{\left(1-V_{m b}\right) D}
$$

Rohatgi et al. (1998) also use the Young-Laplace equation, but they define an other radius $\left(\mathrm{r}_{e}\right)$, which expresses the effective distance between the microballoons [3]. Everything else is the same.

$$
p=\frac{2 \sigma_{l / g} \cos \theta}{r_{e}}=\frac{2 \sigma_{l / g} V_{m b} \cos \theta}{\left(1-V_{m b}\right) D}
$$

This equation is almost the same that was used by Trumble. The Trumble equation can be expressed by multiplying the Rohatgi equation by $6 \lambda$. The largest imperfection of the equations is the lack of considering time dependency.

We calculated the threshold pressure with the equations above. In our case the wetting angle is about $140-150^{\circ}$; that means poor wetting and therefore the listed pressure is required 
for successful infiltration. For the calculations one needs the surface tension of the molten matrix metal, which cannot be measured easily due to quick oxidation of the Al alloys. We used $\sigma_{l / g}=840 \mathrm{mNm}^{-1}$, which is suggested by Kaptay. The results are listed in Table 3

Tab. 3. Threshold pressures according to the different models

\begin{tabular}{cccc}
\hline $\begin{array}{c}\text { Wetting angle } \\
\boldsymbol{\theta}\end{array}$ & \multicolumn{3}{c}{$\begin{array}{c}\text { Threshold pressure } \\
\mathbf{p}, \mathbf{( k P a )}\end{array}$} \\
\cline { 2 - 4 } & Kaptay et al. & Trumble & Rohatgi et al. \\
\hline $\mathbf{1 4 0}$ & 108 & 106 & 18 \\
$\mathbf{1 5 0}$ & 120 & 119 & 20 \\
\hline
\end{tabular}

We used higher infiltration pressures than the calculated threshold pressure, because of the inserted $\mathrm{Al}_{2} \mathrm{O}_{3}$ insulator layer (which must also be infiltrated in order to infiltrate the microballons).

The upper limit of the infiltrating pressure expresses the pressure which can break the microballoons and infiltrate them. Due to this the density will not decrease significantly and therefore the specific properties will not be sufficient. This limit would be expressible by knowing the strength of the microballoons, but the data provided by the manufacturers generally are not reliable. Or it can be determined by experimental measurements, which require sophisticated equipment. In our work the infiltration pressure was at least three times higher than the required threshold pressure in order to ensure good infiltration (without unintended porosity). The experiments showed that this pressure usually did not exceed the strength of the microballons. Some of the produced syntactic foam blocks are shown in Fig. 4.

\section{Experimental methods}

Characterizing property first, the density was determined in several ways. First it was calculated from the mass and the geometrical dimensions of the produced blocks. The precision of mass and length measurements were $0.1 \mathrm{~g}$ and $0.01 \mathrm{~mm}$ respectively. After that density was measured by Archimedes' law and finally it was calculated by the simple rule of mixture (ROM), knowing the density and the real density of the matrix material and microballoons respectively.

After that optical microscopic investigations were done in order to evaluate the infiltration qualitatively. An Olympus PMG-3 type microscope was used for these investigations. The magnification varied between 50 and 1000 . We observed the unintended porosity and the interface between the microballoons and the matrix material.

As the next step, upsetting test specimens were elaborated from the syntactic foam blocks. Three slices with $36 \times 55 \mathrm{~mm}$ cross-section and with different height were cut from each block and six $\varnothing 14 \mathrm{~mm}$ cylindrical specimens from each slice were machined. The heights of the specimens were 14, 21 and $28 \mathrm{~mm}$ determined by the desired aspect ratio: $1 ; 1.5$ and 2 respectively.
This means 108 specimens were compressed ( 2 matrix materials $\times 3$ microballoon types $\times 3$ aspect ratios $\times 6$ specimens). The upsetting tests were done in an upsetting die with a Zwick 50 type universal testing machine. The die had four guide bars in order to minimize the lateral motion and the dies had grinded and polished surfaces. The specimens were lubricated on both sides, and then they were covered with a thin foil of Al and lubricated again. This double lubrication ensured minimal friction between the dies and the specimen. The strain rate was 0.01 $\mathrm{s}^{-1}$ during the upsetting tests, and therefore the upsetting was quasi-static. The tests were conducted until $50 \%$ of engineering deformation was reached.

\section{Results and Discussion}

Density is the most important physical property of every porous materials and therefore metal matrix syntactic foams, too. Density can be determined by different ways. Archimedes' method can be done by two mass measurements. A simpler way is to measure the mass once and then measure the dimensions of the specimens ("geometrical" method). The density is also determinable by calculations using the role of mixture. The calculated densities are represented in Fig. 5

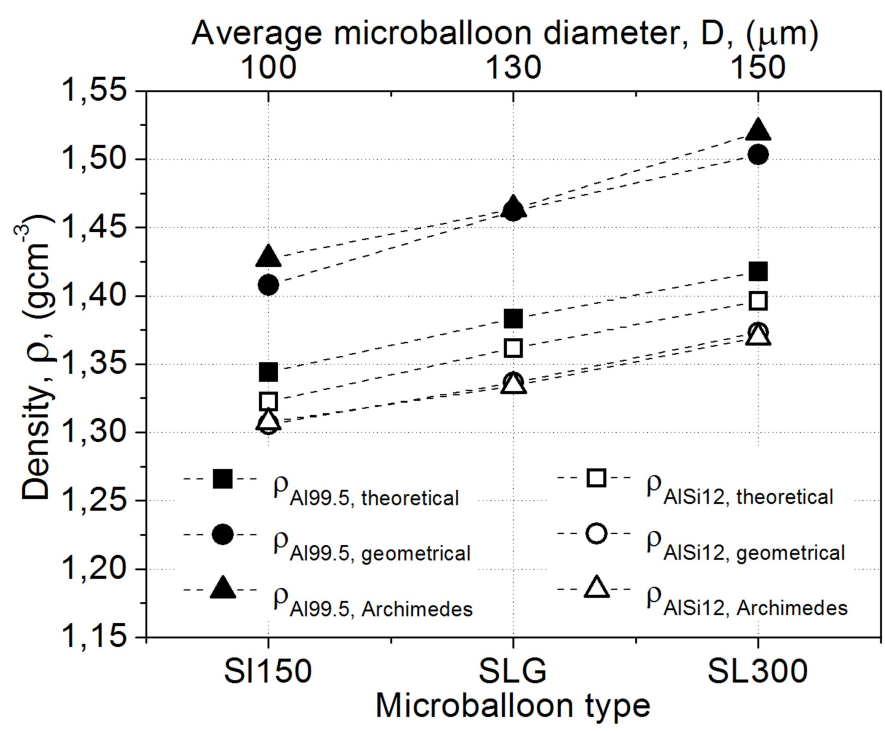

Fig. 5. Density of various syntactic foams

As one can observe the density decreased by $\sim 50 \%$ compared to the matrix materials, because porosity was added to the material. The density grew with an increase in average diameter which means the growth of wall thickness. The difference between the "geometrical" method and measurements according to Archimedes' law was maximum 1\%. But the theoretical density was significantly smaller and higher in the case of A199.5 and AlSi12 matrix material respectively. In the case of A199.5 the theoretical density was smaller, what means that some of the microballoons were infiltrated. The theoretical density of AlSi12 matrix syntactic foams was higher than the measured, what means there is unintended porosity in the foams. The added porosity can be sorted into two groups. Planned poros- 


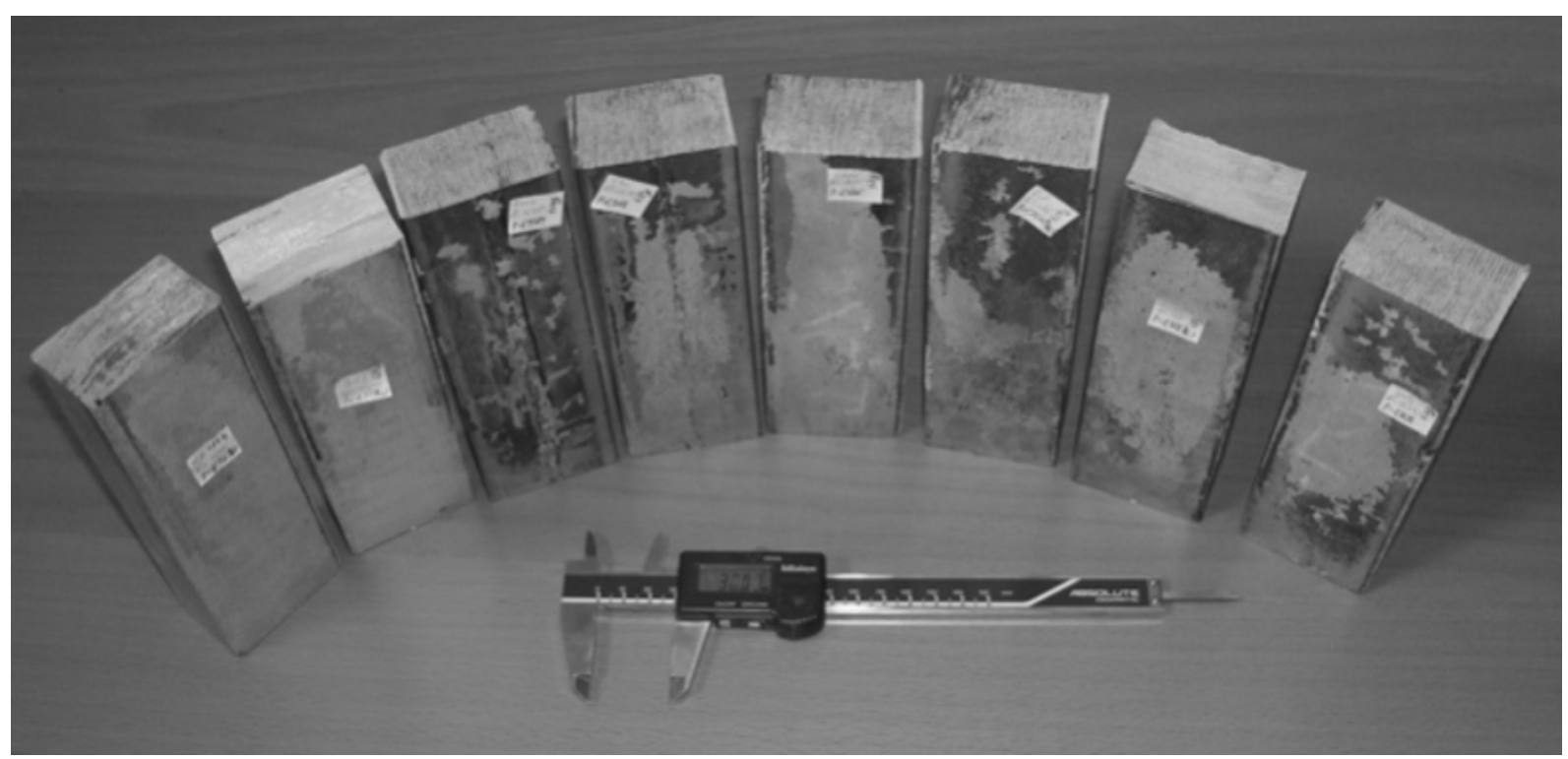

Fig. 4. Some of the produced blocks

ity, which was ensured by the microballoons $\left(\mathrm{P}_{m b}\right)$, and unintended porosity $\left(\mathrm{P}_{u p}\right)$, which was caused by insufficient infiltration between the small microballoons. They can be calculated as follows:

$$
P_{m b}=V_{m b}\left(\frac{r_{i}}{r_{o}}\right)^{3}
$$

where $\mathrm{r}_{i}$ and $\mathrm{r}_{o}$ are the inner and outer radii of the microballoons. And the unintended porosity is calculated as:

$$
P_{u p}=\frac{\rho_{t}-\rho_{m}}{\rho_{t}}
$$

where $\rho_{t}$ and $\rho_{m}$ are the theoretical and measured densities of the syntactic foams. The ideal syntactic foam has no unintended porosity. The total porosity is equal to the sum of planned and unintended porosity.

$$
P_{t p}=P_{m b}+P_{u p}=V_{m g}\left(\frac{r_{i}}{r_{o}}\right)^{3}+\frac{\rho_{t}-\rho_{m}}{\rho_{t}}
$$

The calculated porosities are listed in Table 4

In the case of A199.5 matrix the unintended porosity has negative value, what means that in some cases the infiltration of microballoons happened. And therefore the theoretical density was lower than the measured. This phenomenon may be caused by higher infiltration pressure. In the case of AlSi12 matrix (when the infiltration pressure was lower) the unintended porosity had positive value, what means the pressure was not enough to force the matrix material among the small microballoons therefore unintended porosity became higher and density became lower.

This can also be confirmed by optical microscopy. An example for A199.5 matrix is shown in Fig. 6 A few infiltrated microballoons can be seen in this picture but there are no unintended porosities between the microballoons. The infiltration is perfect, but due to the infiltrated microballoons unintended porosity became negative as shown in Table 4 In Fig.7 AlSi12 metal matrix syntactic foam is shown. Unintended porosities

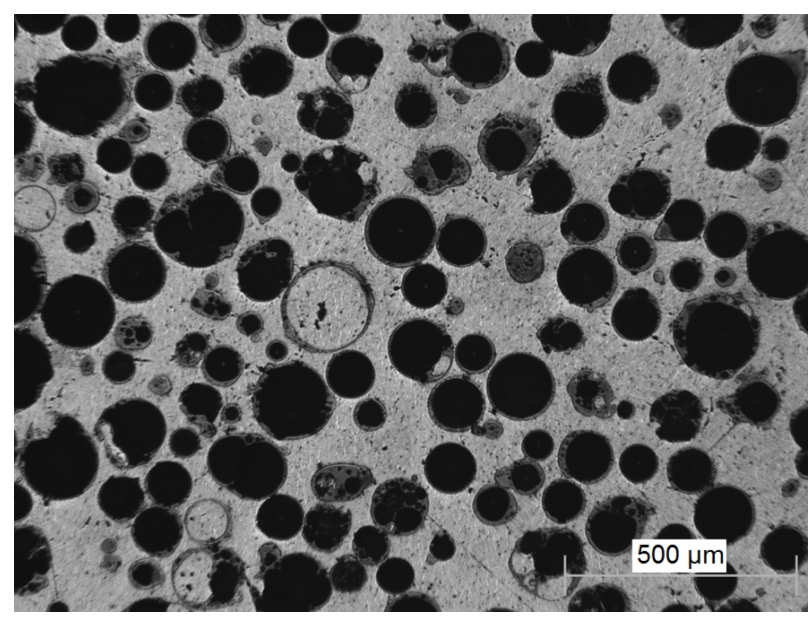

Fig. 6. A199.5 matrix syntactic foam with SL300 filler

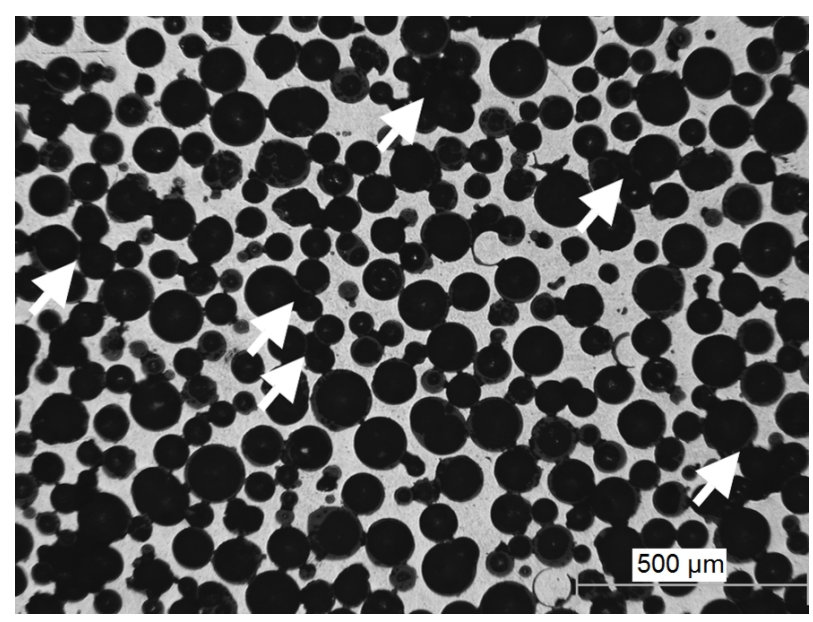

Fig. 7. AlSi12 matrix syntactic foam with SL150 filler

can be clearly separated in the picture. The unintended porosities are formed between the microballoons especially where three microballoons are connected. These places are pointed by white arrows in the picture. In this case the infiltration was not totally perfect, the infiltration pressure was insufficient and the metal matrix was not able to infiltrate the space between fillers 
Tab. 4. Dimensions of the microballons and calculated porosities

\begin{tabular}{|c|c|c|c|c|c|c|}
\hline \multirow{2}{*}{ Designation } & \multirow{2}{*}{ Outer radius } & \multirow{2}{*}{ Inner radius } & \multirow{2}{*}{ Wall thickness } & \multicolumn{3}{|c|}{ Porosity } \\
\hline & & & & Planned & Unintended & Total \\
\hline \multirow[t]{2}{*}{-} & $\mathbf{r}_{b}$ & $\mathbf{r}_{i}$ & $t$ & $\mathbf{P}_{m b}$ & $\mathbf{P}_{u p}$ & $\mathbf{P}_{t p}$ \\
\hline & $(\mu m)$ & $(\mu m)$ & $(\mu m)$ & & & \\
\hline Al-SL150 & 50 & 46.31 & 3.69 & 0.509 & -0.062 & 0.447 \\
\hline Al-SLG & 65 & 59.65 & 5.35 & 0.495 & -0.058 & 0.437 \\
\hline Al-SL300 & 75 & 68.25 & 6.75 & 0.482 & -0.072 & 0.410 \\
\hline AISi-SL150 & 50 & 46.31 & 3.69 & 0.509 & 0.011 & 0.520 \\
\hline AISi-SLG & 65 & 59.65 & 5.35 & 0.495 & 0.020 & 0.515 \\
\hline AISi-SL300 & 75 & 68.25 & 6.75 & 0.482 & 0.019 & 0.501 \\
\hline
\end{tabular}

correctly. This resulted in higher unintended porosity and therefore lower density. Lower density would be advantageous but not by the lack of matrix material.

In some specimens - especially with A199.5 matrix - undisposed microballoons were observed (Fig. 8). This fact indicates that some reaction occurred between the matrix and the microballoons. The material of the microballoons' wall contains mainly $\mathrm{SiO}_{2}$ and $\mathrm{Al}_{2} \mathrm{O}_{3}$. They exist in pure forms and they also form a mullite $\left(3 \mathrm{Al}_{2} \mathrm{O}_{3} \cdot 2 \mathrm{SiO}_{2}\right)$. Molten aluminium alloys are very aggressive chemically and reduce the $\mathrm{SiO}_{2}$ content of the microballoons. This reaction was also reported by Balch and Dunand (2006) [6]. The driving force was the Si concentration between the wall and the matrix.

$$
\begin{aligned}
4 \mathrm{Al}+3 \mathrm{SiO}_{2} & =3 \mathrm{Si}+2 \mathrm{Al}_{2} \mathrm{O}_{3} \Delta G \\
& =302-313 \mathrm{kJmol}^{-1}\left(700-850^{\circ} \mathrm{C}\right)
\end{aligned}
$$

This equation shows $\mathrm{Al}_{2} \mathrm{O}_{3}$ formation, which is advantageous, but not if the price is the disordering of the wall. The elementary $\mathrm{Si}$ was kept in the matrix or appeared as primer Si precipitation. In the case of AlSi12 matrix the spheres have defined contour,

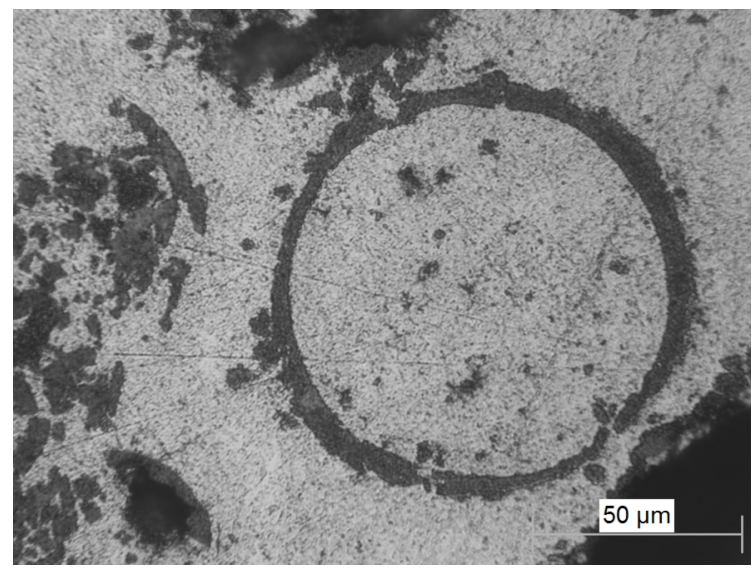

Fig. 8. A199.5 matrix syntactic foam with SL150 filler

and it means there were no significant reactions between them and the matrix. The change reaction was suppressed by the relatively high Si content of the matrix material. This is confirmed by the next picture (Fig. 9). The eutectic microstructure of the matrix material can be observed. The infiltration was perfect

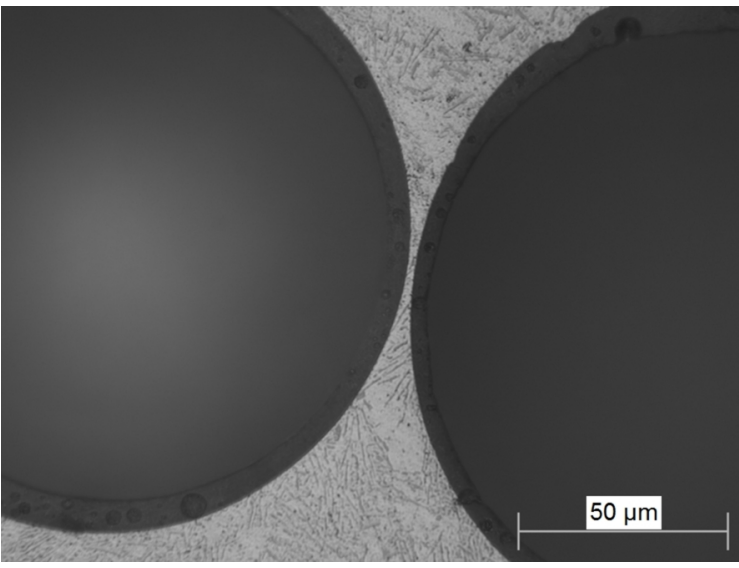

Fig. 9. AlSi12 matrix syntactic foam with SLG filler

among the microballoons. The wall looks unharmed and it indicates that there is no interface layer between the wall and the eutectic matrix.

Upsetting tests were also done to explore the mechanical behaviour and energy absorbing properties of both materials. In case of foams this is the main loading type. Both material types absorbed approximately the same specific mechanical energy $\left(\sim 30-40 \mathrm{Jg}^{-1}\right)$. As every material, syntactic foams also have a specific upsetting diagram. A general upsetting diagram is shown in Fig. 10. The diagram could be divided into three parts. The first part was almost linear. It was easy to fit a line on this part, so an initial compressing modulus could be defined. The first part always ended in a peak. This first peak in the recorded diagram corresponded to the formation of the initial crack in the specimen. Usually the first crack defines the failure of a specimen, but not in case of syntactic foams. After a sudden stress drop ( $20-30 \%)$ they showed a relatively long plateau region, which could be ascending, descending or constant; this was different in every single case. The plateau stress was usually maintained by the sliding of the two specimen-halves (formed by the initial crack) on each other. It ensured high energy absorbing (the area under the upsetting diagram is proportional to the absorbed energy). The plateau region was followed by densification (not showed in the diagram).

The monitored properties were the stress and deformation of 

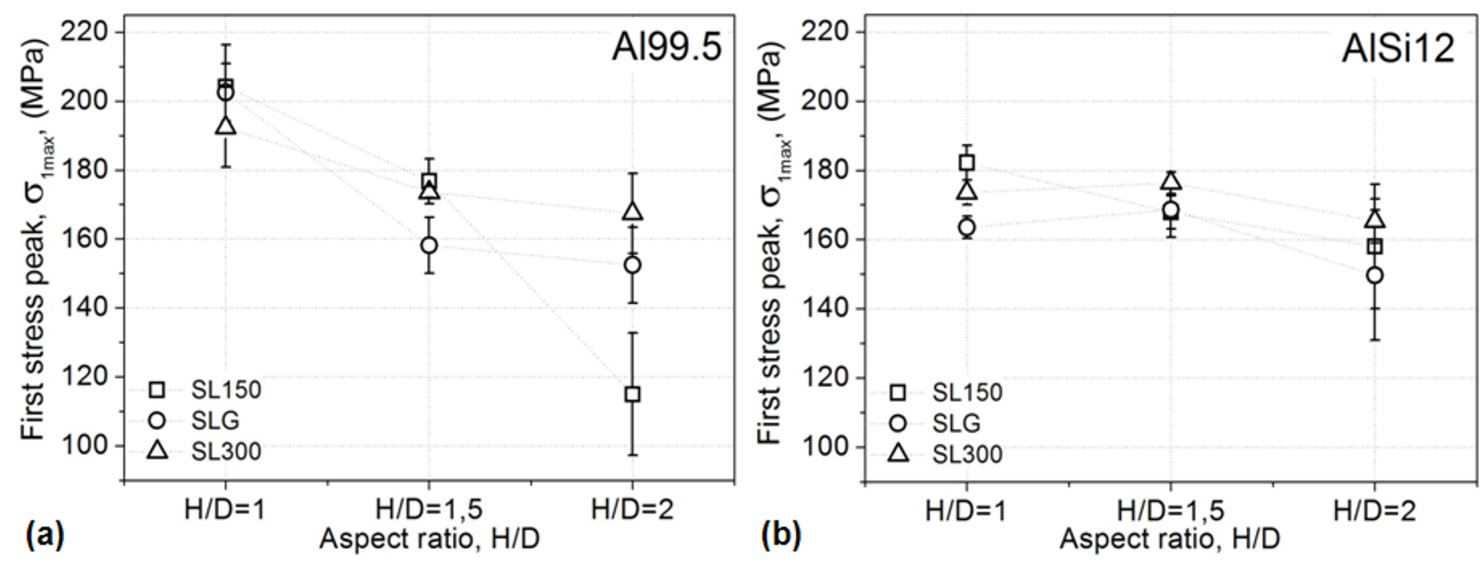

Fig. 11. The change of first peak stress in the function of the aspect ratio and in the case of A199.5 (a) and AlSi12 (b) matrix

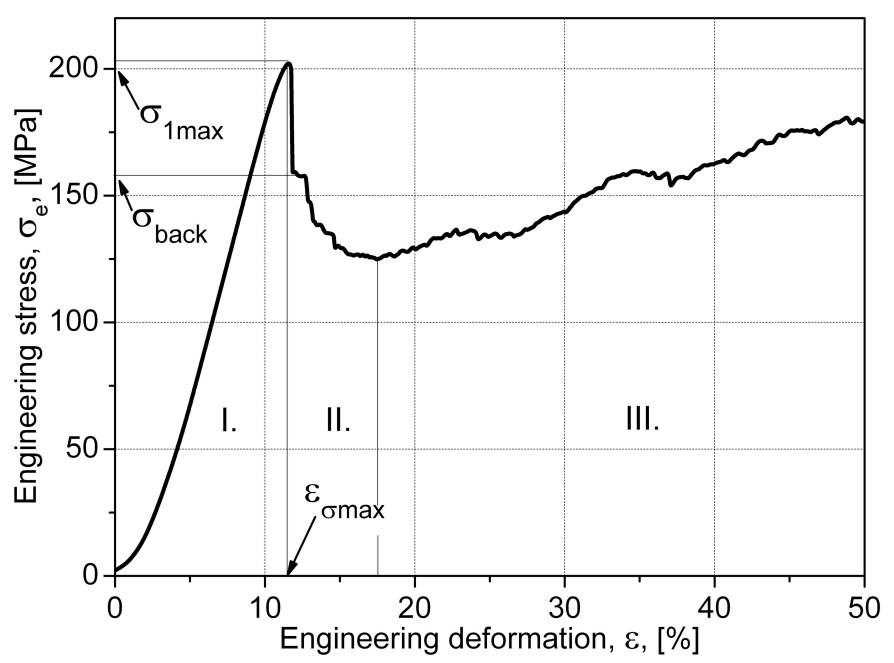

Fig. 10. Typical upsetting diagram of syntactic foams

the first peak $\left(\sigma_{\max }\right.$ and $\left.\varepsilon_{\sigma \max }\right)$ and the initial compressive modulus (E). The values of these parameters were taken from the upsetting diagrams. The following diagrams show the change of peak stress for A199.5 and AlSi12 matrix respectively (Figs. 11 and 11. During upsetting tests the aspect ratio was considered. The shearing effect was increased with a growth in aspect ratio, because the specimens became higher and higher and the small deviations of the specimen and the stress field resulted in an increasing shearing effect. In the case of A199.5 matrix the level of first peak stress strongly decreased between aspect ratio 1 and 1.5. The peak stress decreased further with increase in aspect ratio in the case of SL150 filler, but remained the same in the case of SLG and SL300 fillers. This indicates that at higher aspect ratios the load was carried by the microballoons and SL150 microballoons were simply too weak. Therefore the SL150 microballoons were the most sensitive to the aspect ratio. In the case of AlSi12 matrix the situation was reversed. The SL150 fillers resulted to be the most aspect ratio sensitive foams again. But in the case of SLG and SL300 fillers the peak stresses were almost constant at lower aspect ratios; the microballoons and the matrix carried the load together. After that - at higher aspect ratios - the stress peak decreased. This means AlSi12 matrix tolerated higher shear load than A199.5 matrix, because the effect of shearing (the decrease of peak stress) appeared just in the case of higher aspect ratios.

The deformation at first peak stress was decreased in all cases with an increase in aspect ratio as showed in Fig. 12 .

There were no significant differences between the different fillers; the phenomenon was mainly influenced by the matrix materials. The range of changes was narrower in the case of AlSi12 matrix ( $\sim 5-11 \%)$ and wider in the case of Al99.5 matrix $(\sim 4-12 \%)$. The values were somewhat smaller in the case of the more rigid AlSi12 matrix. According to the decrease of the deformation the modulus were increased as the materials behaved more rigidly by increasing the aspect ratio (Fig. 13).

The compressive modulus increased linearly in all cases. The rate of increase was the same in the case of SL150 and SLG microballoons and a bit higher in the case of SL300. The deformation and modulus measurements revealed that the fillers and matrices have a small effect on these values and they were determined mainly by the aspect ratio.

\section{Conclusions}

From the completed investigations the followings can be concluded:

- Metal matrix syntactic foams can be produced by pressure infiltration. The required theoretical threshold pressure can be determined by several ways. It is recommended to use higher infiltration pressure in order to complete perfect infiltration. At higher pressure a few microballons were infiltrated; the unintended porosity became negative and the density became higher than the theoretical one. At lower pressure the molten matrix material was not able to infiltrate between the microballoons; the unintended porosity was positive and the density became lower than the theoretical one.

- During manufacturing a change reaction occurred, which was diffusion ruled and forced by the Si content mismatch between the microballoons wall and matrix.

- The upsetting diagram of syntactic foams can be divided into three parts. The first part is linear and defines the initial com- 

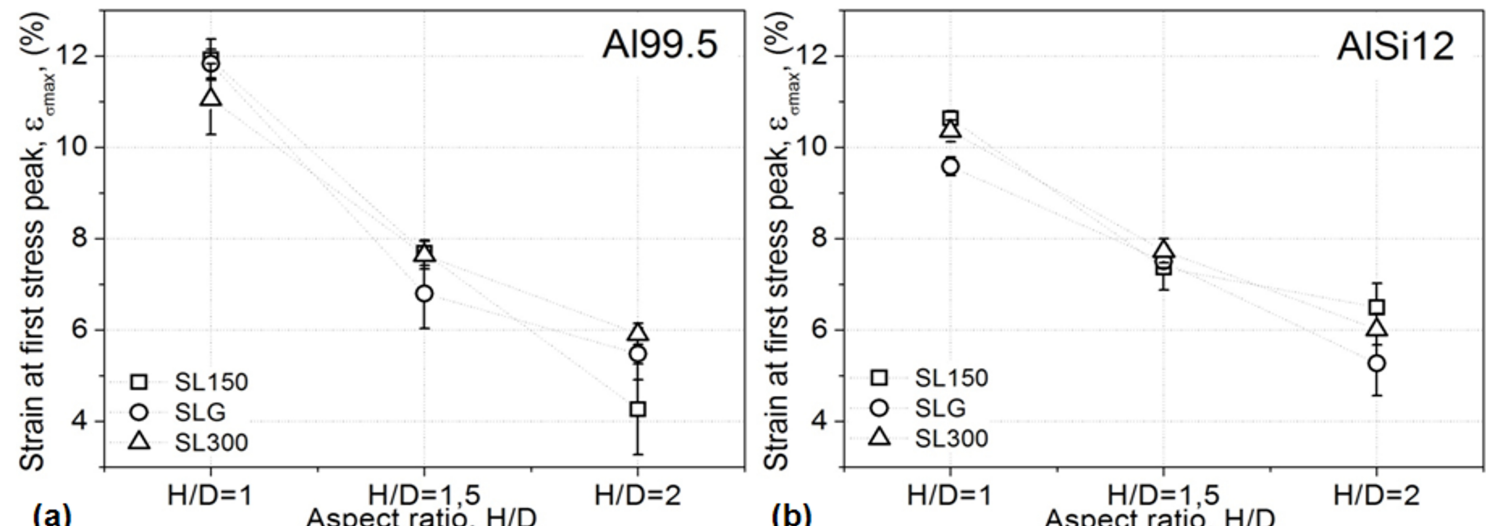

Fig. 12. The change of deformation at first peak in the function of the aspect ratio and in the case of Al99.5 (a) and AlSi12 (b) matrix
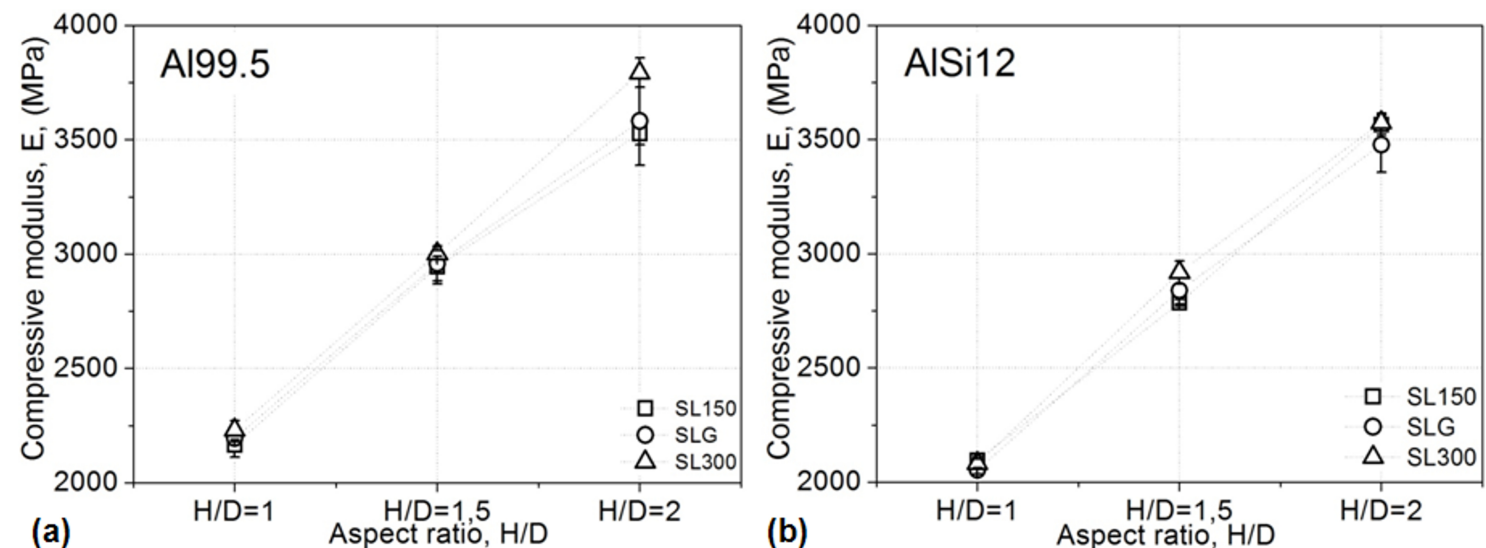

Fig. 13. The change of compressive modulus in the function of the aspect ratio and in the case of Al99.5 (a) and AlSi12 (b) matrix

pressive modulus of the foam. The second part is connected to the formation of the first crack in the specimen. The third part can show various shapes and it is determined by the crack formation and behaviour.

- The upsetting diagrams carry three important parameters, namely first peak stress, according deformation and compressive modulus. These parameters are affected by the aspect ratio of the specimens. Generally, the first peak stress decreased by the aspect ratio. The matrix material and the fillers determine how sensitive the first peak stress is. The deformations at first peak stress decrease with an increase in aspect ratio and the specimens became more brittle and rigid. This was confirmed by the change of the compressive modulus. They were decreasing (almost) linearly with the increase in aspect ratio.

\section{References}

1 Kallas DH, Chatten CK, Buoyancy materials for deep submergence, Ocean Eng. 4 (1969), 421-424, DOI 10.1016/0029-8018(69)90014-6.

2 Ramachandra M, Radhakrishna K, Synthesis - microstructure - mechanical properties - wear and corrosion behaviour of an Al-Si (12\%) fly ash metal matrix composite., J. Mater. Sci. 40 (2005), 5989-5997, DOI 10.1007/s10853-005-1303-6.

3 Rohatgi PK, Guo RQ, Iksan H, Borchelt EJ, Asthana R, Pressure infiltration technique for synthesis of aluminium - fly ash particulate composite, Mater. Sci. Tech. A. 244 (1998), 22-30, DOI 10.1016/S0921-5093(97)008228 .
4 Rohatgi PK, Kim JK, Gupta N, Alaraj S, Daoud A, Compressive characteristics of A356/fly ash cenosphere composites synthesized by pressure infiltration technique, Composites Part A: Appl. Sci. and Manuf. 37 (2006), 430-437, DOI 10.1016/j.compositesa.2005.05.047.

5 Balch DK, O'Qwyer JG, Davis GR, Cady CM, Gray III. GT, Dunand DC, Plasticity and damage in aluminium syntactic foams deformed under dynamic and quasi-static conditions, Mater. Sci. Eng. A. 391 (2205), 408417, DOI 10.1016/j.msea.2004.09.012.

6 Balch DK, Dunand DC, Load partitioning in aluminium syntactic foams containing ceramic microspheres, Acta Mater. 54 (2006), 1501-1511, DOI 10.1016/j.actamat.2005.11.017.

7 Palmer RA, Gao K, Doan TM, Green L, Cavallaro G, Pressure infiltrated syntactic foams - Process development and mechanical properties, Mat. Sci. Eng. A. 464 (2007), 85-92, DOI 10.1016/j.msea.2007.01.116.

8 Bárczy T, Kaptay Gy, Modelling the infiltration of liquid metals into porous ceramics, Mat. Sci. Forum. 473-474 (2005), 297-302, DOI 10.4028/www.scientific.net/MSF.473-474.297.

9 Trumble PK, Spontaneous infiltration of non-cylindrical porosity: closepacked spheres, Acta Mater. 46 (1998), 2363-2367, DOI 10.1016/S13596454(97)00392-3.

10 Kiser M, He MY, Zok FW, The mechanical response of ceramic microballoon reinforced aluminum matrix composites under compressive loading, Acta Mater. 47 (1999), 2685-2694, DOI 10.1016/S1359-6454(99)00129-9.

11 Wu GH, Dou ZY, Sun DL, Jiang LT, Ding BS, He BF, Compression behaviours of cenosphere-pure aluminum syntactic foams, Scripta Mater. 56 (2007), 221-224, DOI 10.1016/j.scriptamat.2006.10.008. 